Buston, H. W. \& Rickard, B. (1956). J. gen. Microbiol. 15, 194-197

\title{
The Effect of a Physical Barrier on Sporulation of Chaetomium globosum
}

\author{
By H. W. BUSTON AND BERYL RICKARD \\ Biochemical Laboratories, Department of Botany, Imperial College of Science \\ and Technology, London, S.W.7
}

SUMMARY: Increased production of perithecia by Chaetomium globosum in the neighbourhood of a physical barrier which impedes the growth of the colony is associated with a locally increased concentration in the medium of organic phosphates excreted by the organism, caused by unequal diffusion of these compounds owing to the presence of the barrier.

It is well known that sporulation of fungi growing in culture media may be stimulated when the mycelium approaches a physical barrier, e.g. the edge of a Petri dish or a channel cut in an agar medium. The subject was studied by Robinson (1926) but no satisfactory explanation of the effect seems yet to have been given. Evidence has accumulated recently that the fruiting of some fungi is stimulated by the presence in the medium of traces of certain organic phosphates (Hawker, 1948; Buston \& King, 1951). Buston \& Khan (1956) showed that some micro-organisms excrete organic phosphates into the medium, and it seemed possible therefore that sporulation might be stimulated by the presence in the medium of organic phosphate excreted by the organism itself; if free diffusion were hindered by the presence of a physical barrier, phosphate might accumulate locally in sufficient concentration to increase sporulation near that point. In order to test the validity of this suggestion the experiments now described were performed.

\section{RESULTS}

The strain of Chaetomium globosum was the stock culture maintained in the laboratory; the cultural methods used were those described by Buston \& King (1951).

Production by Chaetomium globosum of a diffusible substance capable of stimulating formation of perithecia in an adjacent colony of the same organism.

Buston \& Basu (1948) obtained indications that a staled medium in which Chaetomium globosum had grown slightly stimulated production of perithecia in a young colony; a more direct test was made as follows. An inoculum of C. globosum was made $50 \mathrm{~mm}$. from one side of a Petri dish (140 mm. diam.); after incubation at $30^{\circ}$ for $48 \mathrm{hr}$. a second inoculum was made, $30 \mathrm{~mm}$. from the first towards the centre of the dish, and the incubation was continued. In the first colony immature perithecia were evenly distributed in the mycelium within $108 \mathrm{hr}$. The first perithecia in the second colony were visible $84 \mathrm{hr}$. after 
inoculation, and were at first localized in that part of the mycelium nearest the original colony; others appeared in the remainder of the colony about 24 hr. later. Perithecial counts were made on the 10th day in four quadrants of the second colony, and the results are shown diagrammatically in Fig. 1. The quadrant $(a)$ nearest the first colony was distinctly flattened towards the edge, due presumably to the presence of some inhibitory or staling substance produced by the first colony, but production of perithecia was markedly greater than in the other quadrants.

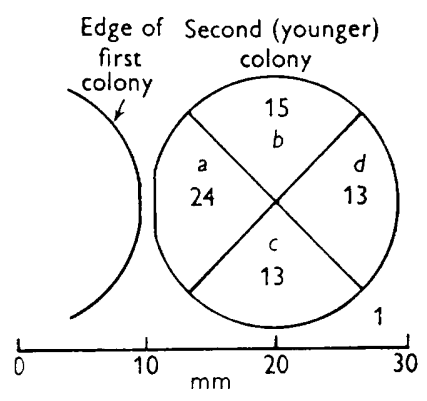

Fig. 1.

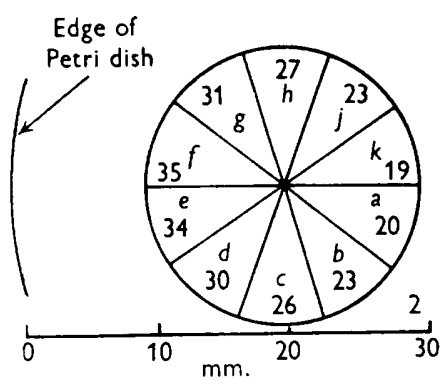

Fig. 2.

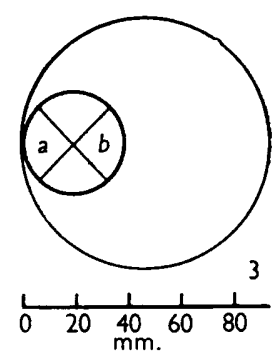

Fig. 3.

Fig. 1. Stimulation of production of perithecia in a colony of Chaetomium globosum in the neighbourhood of another colony of the same organism. The figures in quadrants represent perithecial frequency (average of 10 fields/quadrant in each of 3 plates).

Fig. 2. Stimulation of production of perithecia in a colony of Chaetomium globosum near the edge of the Petri dish. Figures represent perithecial frequency in sectors (average of 3 fields/sector in each of 10 plates).

Fig. 3. Diagrammatic representation of areas in which distribution of organic phosphate was estimated. Inoculum at centre of inner circle.

\section{Increased formation of perithecia near edge of Petri dish}

Petri dishes $90 \mathrm{~mm}$. diameter were used, and inocula of Chaetomium globosum were placed at distances of $10,20,30$ and $40 \mathrm{~mm}$. from the edge. Perithecial counts were made on the 10th day, the colonies being divided into ten equal sectors for this purpose. As shown in Fig. 2, which shows the results obtained at $20 \mathrm{~mm}$., a significantly increased production of perithecia was observed in the sectors ( $e$ and $f$ ) nearest the edge of the dish. When the inoculum was placed $10 \mathrm{~mm}$. from the edge a similar result was obtained but the colony was much flattened towards the edge and the greatest accumulation of perithecia was slightly to each side of the point nearest the edge (i.e. towards sectors $d$ and $g$ ). Maximum perithecial frequencies were of the same order as at $20 \mathrm{~mm}$. When the inocula were placed at distances of $30 \mathrm{~mm}$. or more from the edge, perithecia were evenly distributed throughout the mycelium.

\section{Accumulation of organic phosphates in areas near the colony}

The nature of the organic phosphates excreted by Chaetomium globosum was investigated chromatographically as described by Buston \& Khan (1956). Glucose-6-phosphate, fructose-1,6-diphosphate, and 3-phosphoglyceric 
acid were identified; a small amount of another unidentified phosphate was detected. In order to follow changes in distribution of organic phosphates in different zones of the medium during the growth period, some 60 cultures were prepared, the inoculum in each being placed $20 \mathrm{~mm}$. from the edge of the dish. From the first to the tenth day at least three dishes were taken daily and from each, segments of equal size of the medium were removed: $(a)$ between the point of inoculation and the nearest edge of the Petri dish; $(b)$ from a position symmetrically opposite to this (Fig. 3). Mycelial growth was removed, after which the organic phosphates were extracted from the agar and separated

\section{Table 1. Relative amounts of organic phosphates present in different parts of the medium during growth of Chaetomium globosum}

Immature perithecia in $(a)$ at $84 \mathrm{hr}$., in $(b)$ at $108 \mathrm{hr}$.; mature perithecia in $(a)$ and $(b)$ at $156 \mathrm{hr}$. G-P = Glucose-6-phosphate ; F-P = fructose-1-6-diphosphate； P-G-A=3-phosphoglyceric acid.

Time after
inoculation (hr.)

24
48
72
96
120
144
168
192

(a) Sector near edge of dish

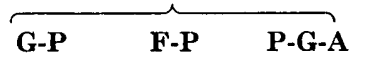

(b) Sector furthest from edge of dish

$\overbrace{\text { G-P } \quad \text { F-P P-G-A }}^{\text {P-P }}$

Relative amounts of organic phosphates

\begin{tabular}{lrrrrr}
\hline 0 & 0 & 0 & 0 & 0 & 0 \\
2 & 1 & $\mathbf{t r}$ & 0 & 0 & 0 \\
4 & 3 & 3 & 0 & 1 & 1 \\
5 & 5 & 6 & 4 & 4 & $\mathbf{t r}$ \\
2 & 4 & $>6$ & 3 & $3 \frac{1}{2}$ & $\mathbf{1}$ \\
0 & $\mathbf{t r}$ & 1 & 0 & $\mathbf{t r}$ & $\mathbf{4} \frac{1}{2}$ \\
0 & 0 & $\mathbf{t r}$ & 0 & 0 & $\mathbf{1}$ \\
0 & 0 & 0 & 0 & 0 & 0
\end{tabular}

chromatographically. The technique of extraction, etc., was standardized so that it was possible to obtain a comparative measure of the amounts of the different phosphates on the chromatogram by using an E.E.L. photoelectric 'scanner'; it was not considered necessary to attempt any determination of absolute quantities since the point at issue was to estimate relative concentrations on opposite sides of the colony. From the results obtained (Table 1) it was evident that organic phosphates accumulated more rapidly and reached a greater concentration near the edge of the Petri dish than on the 'open' side of the colony. In both positions glucose-6-phosphate and fructose-1,6diphosphate were detected before 3-phosphoglyceric acid, which, however, persisted in the medium after the disappearance of the other esters. The rapid decrease in the amount of organic phosphate in the medium at the fifth or sixth day was striking; it coincided approximately with the appearance of mature perithecia, but whether this was more than coincidence remains to be seen. A similar series of experiments in which the inocula were placed at $15 \mathrm{~mm}$. from the edge gave virtually the same results except that maximum concentration of phosphates near the edge was reached some $12 \mathrm{hr}$. earlier. 


\section{DISCUSSION}

The observations now recorded are in agreement with the following suggestions : (1) the appearance of perithecia is associated with the presence of a mixture of organic phosphates in the surrounding medium; these compounds are produced within the mycelium and diffuse outwards; (2) the distribution of perithecia is such as might be expected if free diffusion of the excreted phosphates were impeded by a physical barrier. The intensity of fruiting would appear to be influenced by the state of maturity of the colony and by the distance between the colony and the barrier, these factors together resulting, in favourable circumstances, in a local increase in the concentration of phosphates sufficient to stimulate sporulation.

The experiments here described do not themselves give rigid proof that organic phosphates alone were responsible for the effects noted; their presence is unquestionably associated with production of perithecia but some other substance(s) may have contributed to the stimulatory effect. The local inhibition of growth illustrated diagrammatically in Fig. 1 shows that other active substances are present in the medium, but the well established fact that hexose phosphates in small concentrations can stimulate fruiting affords evidence that they may be directly concerned in the present instance. Previous work (e.g. Buston, Jabbar \& Etheridge, 1953) indicated that the maximum effect is produced when the concentration of phosphate lies within certain rather narrow limits and it is of interest to note that in cultures in which the inoculum was only $10 \mathrm{~mm}$. from the edge of the dish most of the perithecia were formed slightly to left and right of the point nearest the edge, i.e. in sectors $d$ and $g$ rather than $e$ and $f$ (Fig. 2), suggesting that the concentration of organic phosphate in the latter had exceeded the optimum. Where the inoculum was $30 \mathrm{~mm}$. or more from the edge there was less cause for unequal diffusion and a local concentration of phosphates sufficient to affect sporulation did not result.

\section{REFERENCES}

Buston, H. W. \& BASU, S. N. (1948). Some factors affecting the growth and sporulation of Chaetomium globosum and Memnoniella echinata. J. gen. Microbiol. 2, 162.

Buston, H. W., Jabbar, A. \& Etheridge, D. E. (1953). The influence of hexose phosphates, calcium and jute extract on the formation of perithecia by Chaetomium globosum. J. gen. Microbiol. 8, 302.

Buston, H. W. \& KHAN, A. H. (1956). The influence of certain micro-organisms on the formation of perithecia by Chaetomium globosum. J. gen. Microbiol. 14, 655 .

Buston, H. W. \& KIng, E. J. (1951). Further observations on the sporulation of Chaetomium globosum. J. gen. Microbiol. 5, 766.

HAwker, L. E. (1948). Stimulation of the formation of perithecia of Melanospora destruens Shear by small quantities of certain phosphoric esters of glucose and fructose. Ann. Bot., Lond., N.S. 12, 77.

Robinson, W. (1926). The conditions of growth and development of Pyronema confluens Tul. (P. omphaloides (Bull) Fuckel) Ann. Bot., Lond. 40, 245. 